\title{
BMJ Open Weight underestimation linked to anxiety and depression in a cross- sectional study of overweight individuals in a Sami and non-Sami Norwegian population: the SAMINOR Study
}

Kirsti Kvaløy, ${ }^{1,2}$ Marita Melhus, ${ }^{3}$ Anne Silviken, ${ }^{3,4}$ Ann Ragnhild Broderstad ${ }^{3,5}$

To cite: Kvaløy K, Melhus M, Silviken A, et al. Weight underestimation linked to anxiety and depression in a cross-sectional study of overweight individuals in a Sami and non-Sami Norwegian population: the SAMINOR Study. BMJ Open 2019;9:e031810. doi:10.1136/ bmjopen-2019-031810

- Prepublication history and additional material for this paper are available online. To view these files, please visit the journal online (http://dx.doi org/10.1136/bmjopen-2019031810).

Received 21 May 2019 Revised 18 September 2019 Accepted 04 October 2019
Check for updates

(C) Author(s) (or their employer(s)) 2019. Re-use permitted under CC BY-NC. No commercial re-use. See rights and permissions. Published by BMJ.

For numbered affiliations see end of article.

Correspondence to

Dr Kirsti Kvaløy;

kirsti.kvaloy@ntnu.no

\section{ABSTRACT}

Objectives Underestimation of overweight/obesity may prevent weight loss attempts, resulting in further weight gain and maintenance of overweight. Mental health benefits may nevertheless surpass negative consequences. Our main objective was to study the association between underestimation of overweight/ obesity and symptoms of anxiety and depression in Sami and non-Sami populations.

Design Population-based cross-sectional study. Setting The SAMINOR 2 Clinical Study with participants from 10 municipalities in Northern Norway enrolled between 2012 and 2014.

Participants The study included 3266 adults of multiethnic rural origin with overweight/obesity (body mass index $(\mathrm{BMI}) \geq 25 \mathrm{~kg} / \mathrm{m}^{2}$ ) whereof 1384 underestimated their weight (42\%).

Primary and secondary outcome measures Primary outcome measure was symptoms of anxiety and depression and secondary outcome measures were BMI and the demographic variables: sex, age, education and marital status.

Results A higher proportion of Sami men compared with non-Sami men were obese, and reported more symptoms of anxiety and depression. More men than women, and a higher proportion of Sami women compared with nonSami women, underestimated their weight. Multivariableadjusted analyses showed that women were less likely to underestimate their weight compared with men (OR 0.43 , $95 \% \mathrm{Cl} 0.33$ to 0.55 in Sami and OR 0.33, 95\% $\mathrm{Cl} 0.26$ to 0.42 in non-Sami), higher BMI was protective against weight underestimation $(\mathrm{OR} 0.72,95 \% \mathrm{Cl} 0.69$ to 0.75 in Sami and OR 0.63, 95\% Cl 0.60 to 0.67 in non-Sami), slightly higher odds of weight underestimation were observed with increasing age in both ethnic groups (OR $1.03,95 \% \mathrm{Cl} 1.01$ to 1.05 in Sami and OR $1.02,95 \% \mathrm{Cl}$ 1.00 to 1.03 in non-Sami), while higher education lowered the odds in non-Sami ( $0 \mathrm{R} 0.69,95 \% \mathrm{Cl} 0.55$ to 0.87 ). Weight underestimation was protectively associated with anxiety and depression in Sami men $(\mathrm{OR} 0.48,95 \% \mathrm{Cl} 0.27$ to 0.84 ) and in non-Sami women (OR $0.44,95 \% \mathrm{Cl} 0.25$ to 0.78 ) adjusted for age, BMI, education and marital status.
Strengths and limitations of this study

- A strength was that anthropometric measurements were measured electronically by trained personnel avoiding under-reporting or misreporting weight.

- Participation rate was $47 \%$, which was considered satisfactory.

- Adjustments for BMI were added to the analyses to compensate for the wide BMI-range in the combined overweight/obese group that could otherwise bias the weight-perception categorization.

- A limitation was whether true ethnic distribution is reflected, as ethnic definition is based on self-report.

- Symptoms of anxiety and depression were not considered separately.

Conclusions Independent of ethnicity, more men than women underestimated their weight. Underestimation of weight was protectively associated with anxiety and depression in Sami men and non-Sami women.

\section{INTRODUCTION}

Obesity has been increasing globally over several decades creating an enormous health burden on society. ${ }^{1}$ Although recent findings suggest the trend to have stabilised in some populations, ${ }^{2}$ further obesity development or maintenance of present high levels with its linked risk of comorbidities such as type 2 diabetes mellitus, cardiovascular disease, dyslipidaemia and hypertension ${ }^{3}$ would have to be prevented by well-planned public health strategies.

The motivation of weight loss or maintenance of normal weight depends on the individual's realisation of his or her own overweight. Perceiving one's body as slimmer than the actual weight, underestimation, is likely to result in maintenance of overweight 
or further obesity development and therefore also an increased personal health risk. ${ }^{4}$ Factors that influence perception of body weight may depend on sex, culture and socioeconomic conditions, and vary throughout a life course. $^{5}$

The mass media's portrayal of the ideal body in addition to cultural norms influence individuals' and societal expectations of the body image. What is an attractive appearance may vary in a cultural ethnic context and this may again influence the degree of weight misperception in a population. ${ }^{6}$ The indigenous Sami people traditionally living mainly in northern parts of Norway, Finland, Sweden and the Kola Peninsula of Russia embrace a variety of languages, cultures and social conditions largely depending on geographical area. ${ }^{7}$ From traditional occupations linked to reindeer herding, hunting, fishing and farming, employment of most Sami today are similar to non-Sami living in the same geographical areas. Somatic health is also fairly similar comparing the two ethnic groups. ${ }^{8}$

There are not many studies focusing on issues linked to weight misperception in indigenous people such as Sami. However, a study published in 2007 showed that more Sami men compared with urban Finnish and British men liked women with higher BMIs and more 'shapely' bodies. $^{9}$

Weight misperception may have a negative influence on levels of disordered eating and other dysregulated eating behaviours. ${ }^{10}$ Even if no significant differences in disordered eating between Sami and non-Sami living in the same geographical areas were shown in a recent study, ${ }^{11}$ comfort eating was more prevalent among Sami indicating the existence of some ethnic differences concerning this.

Body image dissatisfaction may lower one's self-esteem and thereby negatively influence mental health. In fact, weight perception may be more important than the actual weight status concerning mental health. ${ }^{12}$ Mechanisms linking obesity and depression involve behavioural traits connected to health and appearance concerns. ${ }^{13}$ The latter may be through dissatisfaction with own weight, which is linked to low self-esteem and further to depression. ${ }^{14}$ Several studies have found that individuals with overweight/obesity who underestimate their weight report better quality of life than those who have an accurate weight perception, ${ }^{15-18}$ and recent findings suggest weight underestimation in people with overweight/obesity to be protective against depression. ${ }^{18-20}$ Interestingly, weight underestimation may also protect against future depression indicating weight perception to matter in a causal relationship with depression development. ${ }^{18}$ Therefore, although negatively affecting weight loss initiatives and thereby the somatic consequences of obesity, the psychosocial benefits of weight underestimation may outdistance the health-related disadvantages.

To our knowledge, this is the first study that investigates body image discordance in individuals with overweight/ obesity and the effect on mental health in a multiethnic population in Northern Norway. Sami represent a population with high prevalence of obesity, ${ }^{21}$ and a significantly higher proportion of Sami compared with non-Sami report anxiety and depression symptoms. ${ }^{11}$ Our primary objective was therefore to investigate the relationship between mental health and weight misperception among Sami compared with non-Sami with overweight/obesity. In addition to presumed sex discrepancies, we hypothesised that there are ethnic differences concerning both weight perception in general and related to the association between weight underestimation and symptoms of anxiety and depression.

\section{METHODS \\ The SAMINOR Study}

The Centre for Sami Health Research at UiT The Arctic University of Norway is responsible for The Populationbased Study on Health and Living Conditions in Regions with Sami and Norwegian Populations, the SAMINOR Study, which overall purpose is to gain knowledge on health and living conditions of the indigenous Sami people in Norway. The SAMINOR Study consists of the SAMINOR 1 Survey conducted in 2003-2004 ${ }^{22}$ and the SAMINOR 2 Survey conducted in 2012-2014 carried out in two parts: a questionnaire-based survey in 2012 (the SAMINOR 2 Questionnaire Survey ${ }^{23}$ ) and the SAMINOR 2 Clinical Survey in 2012-2014. ${ }^{24}$ The present study uses data from the SAMINOR 2 Clinical Survey, which includes 10 municipalities $^{24}$ : Karasjok, Kautokeino, Porsanger, Tana, Nesseby, Lyngen, Kåfjord, Storfjord, Skånland and Evenes (online supplementary figure 1). As information on ethnicity is not included in national records, people of all ethnic backgrounds were invited.

All 12455 inhabitants 40-79 years old residing in the municipalities were invited, but due to the questionnaire design, our analyses were restricted to the age range 40-69 years, which included 10399 invitees. A total of 4876 individuals (2198 men and 2678 women) attended the survey, response rate: $46.9 \%$. The survey consisted of a short clinical examination and a questionnaire (available at www.saminor.no). All invitees received a questionnaire in Norwegian. In addition, invitees within the Administrative Area for the Sami Language (Karasjok, Kautokeino, Nesseby and Tana) also received a Northern Sami version of the questionnaire. In Porsanger, Kåfjord and Lyngen, the Sami questionnaire was available on request. Approximately 2 weeks prior to data collection, the invitation letter was posted to invitees; it included an appointment time, an informational brochure and a questionnaire, which contained invitee's assigned study ID. Questionnaires and signed written consent forms were handed in at attendance for clinical examination. ${ }^{24}$

Of an overall sample of 4407 individuals (2029 men and 2378 women) with available data on body mass index (BMI), weight perception, ethnicity and anxiety/depression, 3266 individuals (1645 men and 1621 women) $(74.1 \%)$ were classified with overweight/obesity (BMI 
$\geq 25 \mathrm{~kg} / \mathrm{m}^{2}$ ). Within the overweight/obese sample, 94 individuals $(2.9 \%)$ had missing data on education and 28 individuals $(0.9 \%)$ concerning marital status. As missing data were below $5 \%$ and only found in two of the covariates, no further measures regarding this were taken. Potential bias of analysing the combined sample of overweight and obese individuals were explored doing a sensitivity analysis comprising only the obese individuals $(\mathrm{n}=1274)$.

\section{Ethnicity}

The following 11 questions regarding home language, ethnic background and self-perceived ethnicity/identity were used to define ethnicity: "What language do/ did you/your mother/your father/ [all 4 of] your grandparents speak at home?", "What is your/your father's/ your mother's ethnic background?" and "What do you consider yourself as?" The response options were 'Norwegian', 'Sami', 'Kven' and 'Other'. Several answers could be chosen. Participants were categorised as Sami if they considered themselves Sami and/or that they had Sami ethnic background (Sami self-identification), and in addition reported Sami as home language for at least one grandparent, parent or themselves (Sami language connection). Participants not fulfilling the criteria were categorised as non-Sami. The definitions we have used comply with several recent SAMINOR-based studies. ${ }^{25-27}$ The use of both self-identification (subjective criterion) and language connection (objective criterion) resembles the criteria requested in order to vote or be elected to the Sami Parliament. ${ }^{7}$ However, all categorisations may have different validity in different geographical regions and within different subgroups in the Sami population. ${ }^{22}$

\section{Anthropometry}

Height, weight and BMI were measured using an electronic height and weight scale (DS-103; Dongsahn Jenix, Seoul, Korea) with the participant wearing light clothing without shoes. Height was measured to the nearest $0.1 \mathrm{~cm}$, weight to the nearest $100 \mathrm{~g}$ and BMI $(\mathrm{kg}) /(\text { height }(\mathrm{m}))^{2}$ to the nearest 0.1 unit. BMI was used as a continuous variable in the regression analyses. BMI-based weight categories were as according to WHO: underweight BMI, $<18.5 \mathrm{~kg} / \mathrm{m}^{2}$; normal weight BMI, $18.5-24.9 \mathrm{~kg} / \mathrm{m}^{2}$; overweight BMI, $25-29.9 \mathrm{~kg} / \mathrm{m}^{2}$; obesity BMI, $\geq 30 \mathrm{~kg} / \mathrm{m}^{2}$.

\section{Weight perception}

Body weight misperception was defined as a self-reported body weight perception that was inconsistent with the participant's BMI. The weight perception variable was deduced from the question "How would you describe yourself?" by selecting one of the five following response options: 'Extremely fat', 'Too fat', 'Average/Just right', 'Too thin/Skinny' and 'Extremely thin/Skinny'. Weight status perception was further collapsed into a variable reflecting accurate weight perception or weight misperception where the latter could be underestimation or overestimation of weight.
Individuals with overweight/obesity who selfcategorised themselves as 'Average/Just right', 'Too thin/Skinny' or 'Extremely thin/Skinny' were defined as misperceiving their weight by underestimation. Individuals with overweight or obesity that categorised themselves as 'Extremely fat' or 'Too fat' were considered as perceiving their weight accurately. Weight overestimation, that is, in this context overweight individuals who reported themselves as 'Extremely fat', was not taken into account due to the low occurrence $(n=10)$. The present paper only includes study participants with overweight/ obesity and hence on potential underestimation of weight.

As perception of weight largely correlates to actual weight, individuals defined as either overweight or obese $\left(\mathrm{BMI} \geq 25 \mathrm{~kg} / \mathrm{m}^{2}\right.$ ) will comprise individuals who are slightly overweight until those who are considerably obese. This may infer a bias concerning degree of misperceiving one's weight.

\section{Anxiety and depression}

The five-item Hopkins Symptom Checklist (SCL-5) was used to assess symptoms of anxiety and depression. The SCL-5 has previously been developed and validated as a short version of the SCL-25 scale, ${ }^{28}{ }^{29}$ but has not been validated in Sami. On a four-point Likert scale ranging from 1 ('Not bothered') to 4 ('Very much bothered'), participants were asked about symptoms during the past 4 weeks: 'Nervousness or shakiness inside', 'Feeling fearful', 'Feeling hopeless about the future', 'Worrying too much about things' and 'Feeling blue'. An average item score of 2.0 or higher was used to identify anxiety and depression, following previous suggestions. ${ }^{29}$ Participants who answered only four of the five questions $(n=52)$ were also included.

\section{Education}

Education was assessed by the question "How many years of education have you completed? (Include all years in which you attended school or studied)". Number of education years was dichotomised into 'high' $\geq 13$ years and 'low' $<13$ years.

\section{Marital status}

Marital status was assessed by the question "What is your marital status?" with the following five answer options: 'married', 'cohabitant', 'divorced', ' 'unmarried'4 and 'widow/widower'. ${ }^{5}$ The variable was dichotomised into 'married' combining 1 and 2 and 'single' combining 3-5.

\section{Statistics}

All statistical analyses were performed using IBM SPSS Statistics for Windows, V.25.0, most often performed separately for men and women and ethnic belonging. Ethnic differences were tested by Pearson's $\chi^{2}$ tests. Potential interactions between weight perception $\times$ sex were tested in the ethnic-stratified analyses, and between weight perception $\times$ ethnic origin in the sex-stratified analyses. 
Associations between body weight underestimation and the demographic factors (age, education and marital status) and between weight underestimation and anxiety and depression were analysed with multivariable logistic regressions. Continuous BMI was included as adjustment in the binary regression analyses to take account for the quite extensive BMI range in the sample of both overweight and obese individuals (BMI $\geq 25 \mathrm{~kg} / \mathrm{m}^{2}$ ). ORs with 95\% CIs are presented and level of significance set at 0.05 . We used the STROBE cross-sectional checklist when writing our report. ${ }^{30}$

\section{Patient and public involvement statement}

This research did not include patients, but data from participants who have consented to participate in the SAMINOR Study. The Centre for Sami Health Research consulted with the Sami Parliament during planning and initiation of data collection of all the SAMINOR surveys. During the period of planning, researchers and health workers who work within Sami core areas or are Sami themselves were conferred with to meet the needs of the Sami community. The SAMINOR Project Board approved the specific study described. The public was not invited to comment on the study design and was not consulted to develop relevant outcomes or interpret the results, neither were they invited to contribute to the writing or editing of this document for readability or accuracy.

\section{RESULTS}

\section{Descriptive statistics}

Ethnic- and sex-specific characteristics of the 3266 study participants with overweight/obesity $(74.2 \%$ of the total sample), 1393 Sami (42.7\%) (F: 709, M: 684) and 1873 non-Sami (57.3\%) (F: 912, M: 961), are shown in table 1. The distribution concerning 10-year age groups and high and low education among Sami and non-Sami participants were the same. Among the men with overweight/ obesity, a significantly higher proportion of the individuals with obesity (BMI $\geq 30 \mathrm{~kg} / \mathrm{m}^{2}$ ) was found within Sami compared with the non-Sami $(40.1 \%$ vs $34.8 \%)$ $(\mathrm{p}=0.028)$. Likewise, a significantly higher proportion of Sami compared with non-Sami men with overweight/ obesity reported symptoms of anxiety and depression $(11.7 \%$ vs $7.8 \%)(\mathrm{p}=0.008)$, and this difference was even more pronounced in the group with obesity (BMI $\geq 30$ $\left.\mathrm{kg} / \mathrm{m}^{2}\right)(15.7 \%$ vs $8.1 \%) \quad(\mathrm{p}=0.003) \quad$ (online supplementary table 1$)$.

\section{Weight perception and association between underestimation of weight and demographic factors}

A very high proportion of participants with overweight/ obesity (BMI $\geq 25 \mathrm{~kg} / \mathrm{m}^{2}$ ) underestimated their weight in our population. Within the group categorised with obesity $\left(\mathrm{BMI} \geq 30 \mathrm{~kg} / \mathrm{m}^{2}\right), 25.7 \%$ men and $11.3 \%$ women underestimate their weight (online supplementary table 1). The proportion of Sami women who underestimated their weight in the overweight/obese group was significantly higher compared with non-Sami women (34.4\% vs $29.8 \%)$ $(\mathrm{p}=0.049)($ table 1$)$ and in the group with obesity $(16.1 \%$ vs $7.0 \%)(p<0.001)$ (online supplementary table 2$)$. For men with overweight/obesity, however, there were no ethnic differences in weight perception (table 1), while in the obese-only group, a significantly higher proportion of Sami men compared with non-Sami men underestimated their weight $(30.7 \%$ vs $21.6 \%) \quad(p=0.011)$ (online supplementary table 1$)$.

To investigate what demographic factors (sex, age, education level and marital status) influence weight underestimation in overweight/obese, multivariable logistic regression analyses adjusted for BMI stratified on Sami and non-Sami were performed. As expected from the initial $\chi^{2}$ tests, women were more likely to estimate their weight accurately compared with men, that is, being female protected against underestimation of weight (OR $0.43,95 \%$ CI 0.33 to 0.55 in Sami and OR 0.33 , 95\% CI 0.26 to 0.42 in non-Sami, $\mathrm{p}<0.001$ ) (table 2). In both ethnic groups, the odds of underestimation increased slightly by age, OR 1.03 , 95\% CI 1.01 to 1.05 in Sami $(p<0.001)$ and OR 1.02, 95\% CI 1.01 to 1.03 in non-Sami $(\mathrm{p}=0.044)$. Higher education had only protective effects on underestimation in the non-Sami individuals (OR $0.69,95 \%$ CI 0.55 to $0.87, \mathrm{p}=0.002)$. As expected, weight underestimation was less likely in individuals with lower compared with higher BMI and the effect was independent of ethnicity (OR $0.72,95 \%$ CI 0.69 to 0.75 , $\mathrm{p}<0.001$ in Sami and OR 0.63, 95\% CI 0.60 to $0.67, \mathrm{p}<0.001$ in nonSami). Marital status did not affect the results (table 2).

\section{Association between underestimation of weight and symptoms of anxiety and depression}

To study the association between weight underestimation and symptoms of anxiety and depression, multivariable logistic regression models were run stratified on sex and ethnicity. The results displayed both ethnic-specific and sex-specific differences (table 3 and figure 1). To test if these differences were backed up statistically, the interaction between weight perception $\times$ sex was tested in the ethnic stratified analyses, and between weight perception $\times$ ethnic origin in sex stratified analyses. The interactions between weight perception $\times$ sex were near significance in the non-Sami $(p=0.050)$ and between weight perception $\times$ ethnicity in women in general $(\mathrm{p}=0.056)$.

When adjusted for age, BMI, education and marital status, having symptoms of anxiety and depression was negatively associated with underestimating one's weight both in Sami men (OR 0.48, 95\% CI 0.27 to 0.84, $\mathrm{p}=0.010$ ) and non-Sami women (OR $0.44,95 \% \mathrm{CI} 0.25$ to $0.78, \mathrm{p}=0.005$ ) (table 3 and figure 1 ). The protective effect towards having anxiety and depression symptoms when underestimating weight was strengthened by higher education and being married/cohabiting in both groups (models 3 and 4 in online supplementary table 2). BMI did not affect the associations (model 2 in online supplementary table 2 ). 
Table 1 Sample characteristics of the overweight and obese study sample $(n=3266)$

\begin{tabular}{|c|c|c|c|c|c|c|}
\hline & \multicolumn{3}{|l|}{ Men } & \multicolumn{3}{|l|}{ Women } \\
\hline & Sami & Non-Sami & Total & Sami & Non-Sami & Total \\
\hline & $(n=684)$ & $(n=961)$ & $(n=1645)$ & $(n=709)$ & $(n=912)$ & $(n=1621)$ \\
\hline & n (\%) & n (\%) & n (\%) & n (\%) & n (\%) & n (\%) \\
\hline \multicolumn{7}{|l|}{ Age (years) } \\
\hline $40-49$ & 177 (25.9) & $236(24.6)$ & $413(25.1)$ & $195(27.5)$ & $272(29.8)$ & 467 (28.8) \\
\hline $50-59$ & 227 (33.2) & $314(32.7)$ & 541 (32.9) & $256(36.1)$ & 292 (32.0) & 548 (33.8) \\
\hline $60-69$ & 280 (40.9) & $411(42.8)$ & 691 (42.0) & $258(36.4)$ & 348 (38.2) & 606 (37.4) \\
\hline$P$ value* & & & 0.730 & & & 0.220 \\
\hline \multicolumn{7}{|l|}{ BMI category } \\
\hline Overweight & 410 (59.9) & 627 (65.2) & $1037(63.0)$ & $399(56.3)$ & $556(61.0)$ & 955 (58.9) \\
\hline Obese & $274(40.1)$ & $334(34.8)$ & $608(37.0)$ & $310(43.7)$ & $356(39.0)$ & 666 (41.1) \\
\hline$P$ value* & & & 0.028 & & & 0.057 \\
\hline \multicolumn{7}{|l|}{ Weight perception } \\
\hline Accurate & $317(46.3)$ & $460(47.9)$ & 777 (47.2) & $465(65.6)$ & $640(70.2)$ & $1105(68.2)$ \\
\hline Underestimation & $367(53.7)$ & $501(52.1)$ & $868(52.8)$ & $244(34.4)$ & $272(29.8)$ & $516(31.8)$ \\
\hline $\mathrm{P}$ value ${ }^{*}$ & & & 0.542 & & & 0.049 \\
\hline \multicolumn{7}{|l|}{ Anxiety/depression } \\
\hline$<2.0$ & $604(88.3)$ & $886(92.2)$ & 1490 (90.6) & $602(84.9)$ & $804(88.2)$ & $1406(86.7)$ \\
\hline$\geq 2.0$ & $80(11.7)$ & $75(7.8)$ & $155(9.4)$ & $107(15.1)$ & $108(11.8)$ & 215 (13.3) \\
\hline$P$ value* & & & 0.008 & & & 0.056 \\
\hline \multicolumn{7}{|l|}{ Education (years) } \\
\hline$<13$ & $403(58.9)$ & $549(57.1)$ & $952(57.9)$ & $327(46.1)$ & $463(50.8)$ & $790(48.7)$ \\
\hline$\geq 13$ & $258(37.7)$ & $388(40.4)$ & $646(39.3)$ & $358(50.2)$ & $426(46.7)$ & $784(48.4)$ \\
\hline Missing & 23 & 24 & & 24 & 23 & \\
\hline$P$ value* & & & 0.340 & & & 0.087 \\
\hline \multicolumn{7}{|l|}{ Marital status } \\
\hline Married/cohabit & $482(71.4)$ & 746 (78.3) & $1228(75.4)$ & $485(68.8)$ & 701 (77.5) & $1186(73.7)$ \\
\hline Single & $193(28.6)$ & 207 (21.7) & $400(24.6)$ & 220 (31.2) & $204(22.5)$ & $424(26.3)$ \\
\hline Missing & 9 & 8 & & 4 & 7 & \\
\hline P value & & & 0.002 & & & $<0.001$ \\
\hline BMI (mean, SD) & $29.8( \pm 3.6)$ & $29.4( \pm 3.6)$ & $29.6( \pm 3.6)$ & $30.3( \pm 4.3)$ & $29.8( \pm 4.1)$ & $30.0( \pm 4.2)$ \\
\hline $\begin{array}{l}\text { Waist circumference } \\
\text { (mean, SD) }\end{array}$ & $101.6( \pm 9.6)$ & $102.6( \pm 9.9)$ & $102.2( \pm 9.8)$ & $97.7( \pm 10.3)$ & $97.6( \pm 9.6)$ & $97.6( \pm 9.9)$ \\
\hline
\end{tabular}

*Ethnic difference tested by Pearson's $\chi^{2}$ test and $\mathrm{p}$ values are presented.

BMI, body mass index.

\section{DISCUSSION}

Accurate perception of one's overweight or obesity is important for weight reduction attempts and prevention of future weight gain. A recent British study showed that as high as $85 \%$ of individuals with overweight or obesity who underestimated their weight were less likely to try to lose weight compared with accurate weight-perceiving peers. ${ }^{31}$ Underestimation of weight in individuals with obesity has, however, been associated with better mental health. ${ }^{18}$ Thus, along with pointing out overweight/ obesity to prevent further obesogenic development, the potential detrimental effects on mental health of correcting weight misperceptions need to be considered.

In our study, we aimed to examine the prevalence of weight underestimation and to investigate what factors influence weight underestimation in individuals with overweight/obesity in an adult population of Sami and non-Sami individuals inhabiting shared regions in northern Norway. We further wanted to study the associations between underestimation of weight with symptoms of anxiety and depression. 
Table 2 Odds for body weight underestimation in Sami and non-Sami participants with overweight/obesity considering BMI and selected demographic variables (presented as ORs with 95\% Cls)

\begin{tabular}{|c|c|c|c|c|c|c|c|c|}
\hline & \multicolumn{4}{|l|}{ Sami (n=1335) } & \multicolumn{4}{|l|}{ Non-Sami $(n=1811)$} \\
\hline & OR $(95 \% \mathrm{Cl})$ & B & SE & $P$ value & OR $(95 \% \mathrm{Cl})$ & B & SE & $P$ value \\
\hline Men (ref)/women & $0.43(0.33$ to 0.55$)$ & -0.851 & 0.13 & $<0.001$ & 0.33 (0.26 to 0.42$)$ & -1.106 & 0.12 & $<0.001$ \\
\hline BMI (continuous) & 0.72 (0.69 to 0.75$)$ & -0.328 & 0.02 & $<0.001$ & 0.63 (0.60 to 0.67 ) & -0.457 & 0.03 & $<0.001$ \\
\hline $\begin{array}{l}\text { Low (ref)/high } \\
\text { education }\end{array}$ & $0.82(0.63$ to 1.06$)$ & -0.202 & 0.13 & 0.126 & 0.69 (0.55 to 0.87$)$ & -0.370 & 0.12 & 0.002 \\
\hline
\end{tabular}

The associations between weight underestimation and selected demographic variables are adjusted for age, BMI, education and marital status.

B, unstandardised regression coefficient; BMI, body mass index; OR, odds ratio; SE, standard error.

We found that a higher proportion of men underestimated their weightcompared with women. However, Sami women were more likely than their non-Sami counterparts to underestimate their weight. Underestimation of weight was only significantly protective against anxiety and depression in Sami men and non-Sami women. Although not statistically significant, the same trends were also identified in Sami women and non-Sami men.

To our knowledge, there has been no studies concerning weight misperception among the Sami population. Previous findings of both obesity ${ }^{1121}$ and disordered eating ${ }^{11}$ comparing the Sami and nonSami populations, however, indicated just minor ethnic discrepancies although a higher proportion of Sami women compared with non-Sami women were obese $\left(\mathrm{BMI} \geq 30 \mathrm{~kg} / \mathrm{m}^{2}\right) .{ }^{11}$ Perception of weight has changed over time and may vary in a cultural and ethnic context. ${ }^{5}$ Addressing this issue properly is, however, difficult as study samples are very heterogeneous and large datasets hard to come by. There are studies based on data from the USA that demonstrate differences in weight misperception in a cultural ethnic context. In a large study of whites, blacks, US-born Mexican Americans and Mexican immigrants to the USA, whites were more likely than the ethnic minorities to perceive themselves as overweight at both time periods, 1988-1994 and 1999-2008, included. ${ }^{5}$ In another study from 1999 to 2002, blacks with overweight/obesity were $50 \%$ and Hispanics $70 \%$ more likely to underestimate their overweight compared with whites even after correction for age, education, income, marital status, self-reported health and self-reported medical diagnosis of overweight. ${ }^{32}$ Even if sociocultural factors that favour heavier body image ideals may be present, it is unknown whether general ethnic and/or gender differences concerning weight satisfaction exist or whether the awareness of overweight/obesity differs in this context. ${ }^{32}$ In Sami, no studies directly addressing body image or weight perception or factors that could influence this exist at present; however, Sami exposed to discrimination have shown higher odds of obesity, ${ }^{33}$ and one may speculate whether underlying psychological stressors could also affect factors influencing weight satisfaction and mental health. In a study of ethnic discrimination and health, ${ }^{33}$ sex differences concerning discrimination related to obesity was linked to whether the Sami were in majority or minority in his/her municipality. This is interesting and worth pursuing in follow-up studies of our findings related to ethnic differences between the sexes. The issue concerning differential body image perception in Sami and non-Sami will be possible to investigate due to a modified version of the Stunkard Figure Rating Scale ${ }^{34}$ included in the questionnaire of the SAMINOR 2 Clinical Survey. ${ }^{24}$

In both men and women, a very high proportion of individuals with overweight or obesity in our study population underestimated their weight. More men $(\sim 53 \%)$ than women $(\sim 30 \%)$ perceived their weight inaccurately, and significantly more Sami women (34.4\%) compared with non-Sami women $(29.8 \%)$ underestimated their overweight/obesity. The discrepancy between women and men highly agrees with most studies published, and many of these are based on different ethnic populations. ${ }^{4135-37}$ A study of Caribbean adults aged $>40$ years, however, showed equal sex distribution. ${ }^{38}$ The authors of the latter study argue that part of the explanation for the observed equal distribution between men and women may be that the general view within this community is that overweight is actually desirable.

Some demographic factors seem to influence weight underestimation. In our study, underestimation increased slightly by age, and this is also observed in several other studies. ${ }^{48} 39$ Higher education, which is often considered a proxy for higher socioeconomic status, was protective of underestimation in the non-Sami with overweight/obesity, and this is in accordance with findings of previous studies. ${ }^{4} 313839$ Hassan $e t a l^{8}$ argue that the variation concerning perception of overweight/obesity and education may be due to obesity rates in general being linked to lower education levels in high-income countries as opposed to high education in low-income/ middle-income countries. That both Sami and non-Sami with lower education seem to be more predisposed to 


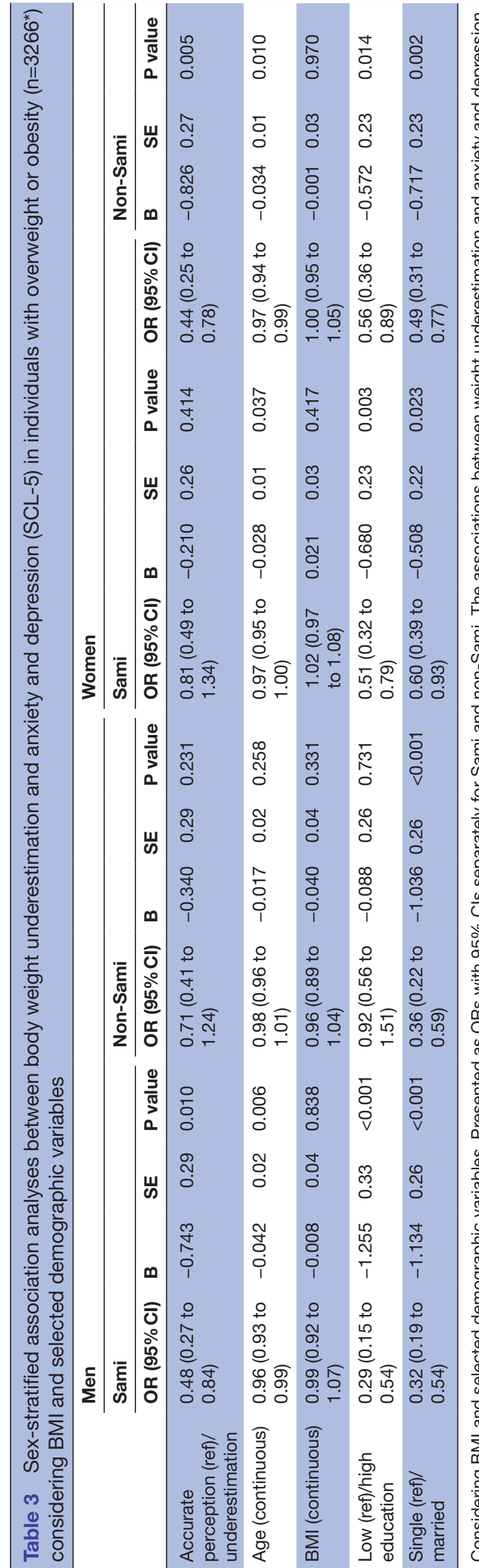

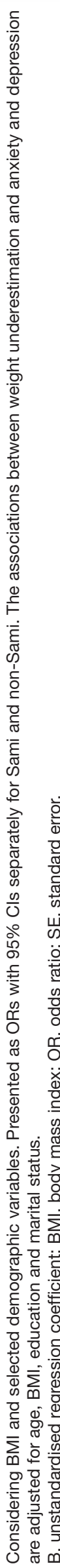

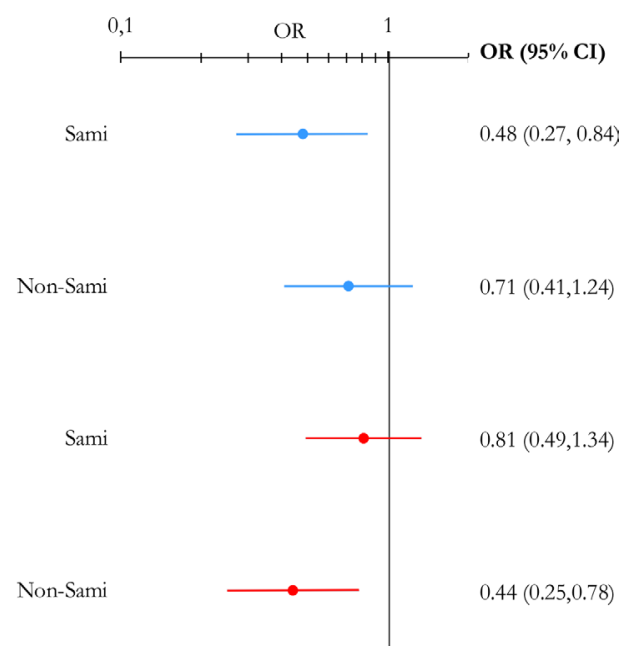

Figure 1 Odds for symptoms of anxiety and depression in individuals with overweight/obesity who underestimate their weight vs those with accurate weight perception. Presented separately for Sami and non-Sami men (blue) and women (red), considering body mass index and selected demographic variables (age, education and marital status).

weight underperception acknowledges the fact that both populations are comparable with other high-income populations.

We found no effects concerning the potential influence of marital status on the overweight underestimation. Others have found that married individuals seem to underestimate their overweight/obesity to a larger extent, ${ }^{4}$ and in a study of US adults, married or former married women overestimated their weight, while men's marital status was in general not associated with weightrelated perceptions and behaviours. ${ }^{40}$ According to Jang et $a l,{ }^{4}$ the social pressure towards obtaining an ideal body shape decline at marriage and the weight ideals may change for the purpose of health rather than looks.

We found that weight underestimation in individuals with overweight/obesity is protective against symptoms of anxiety and depression in Sami men and non-Sami women. Several other studies have shown the occurrence of less depression symptoms in individuals with overweight/obesity who perceive their weight as average or normal compared with accurate-weight perceivers. ${ }^{\text {I2 }} 1820$ The association between weight perception and depression is suggested to be related to weight stigma and labelling. ${ }^{41-43}$ Individuals with obesity often encounter this in settings related to social relationships, schools, workplaces and the healthcare system, ${ }^{44}$ and what is very important to bear in mind is-as Cash points out-the subjective experience of an individual's appearance is more psychosocially important than the socially or objectively assessment of appearance. ${ }^{45}$ As mentioned earlier, weight perception and the consequences of this may vary in men and women. In a study of Korean adults, underperception of weight status in individuals with obesity was inversely associated with depression in women, but not in men. ${ }^{20}$ In a Korean study including younger individuals, 
male students who underestimated their body weight and female students who overestimated their body weight were shown to have greater risks of depression compared with their peers with accurate weight perceptions. Interestingly, the females' perception of overweight was associated with depression symptoms regardless of actual weight ${ }^{46}$ which was in agreement with earlier comparable studies. ${ }^{47} 48$

The ethnic differences observed in our study related to gender concerning underestimation of overweight/ obesity and symptoms of anxiety and depression were difficult to explain. The consequences of the 'Norwegianization' (assimilation policy), cultural marginalisation and increasing pressure of conformity that have occurred in the past, affecting many generations of Sami, may also presumably have influenced men and women differently. In a previous study based on the same population, more symptoms of disordered eating (DE) was reported in Sami compared with non-Sami men as well as stronger associations between DE and lower education, lower physical activity and higher consumption of snacks. ${ }^{11}$ These findings could reflect differential factors influencing perception of overweight and body image in Sami versus non-Sami men and women. In our present study, there are small ethnical-related discrepancies that should be considered in this respect. In men, the Sami with overweight/obesity consisted of a higher proportion of individuals with obesity versus overweight compared with non-Sami. In addition, Sami men with overweight/ obesity were more likely to report symptoms of anxiety and depression (11.7\% in Sami vs $7.8 \%$ in non-Sami). In women with obesity (BMI $\geq 30 \mathrm{~kg} / \mathrm{m}^{2}$ ), the proportion that underestimated their weight were significantly higher in Sami compared with non-Sami women $(16.1 \%$ in Sami vs $7.0 \%$ in non-Sami).

\section{Strengths and limitations}

In our investigation, a strength was that the anthropometric measurements were measured electronically by trained personnel avoiding under-reporting or misreporting weight. ${ }^{49}$ We further consider the participation rate of $47 \%$ to be satisfactory. Participation rate increased with age and results are therefore more uncertain in general for the younger age groups.

A limitation of our study is whether true ethnic distribution is reflected in our sample. Due to the prohibited registration of ethnic relationship in Norwegian public records, accurate information on ethnicity is hard to obtain. Our ethnic definition is based on self-report where Sami defined participants had to consider themselves as Sami or acknowledge Sami ethnic background. In addition, Sami as a home language in at least one person in the past three generations had to be reported which ensured an objective relation to the Sami. As no information is available about the ethnic background of nonrespondents, we do not know whether participation rates of Sami and non-Sami differ. Previous studies of the same material have shown that participation was generally high in Sami-dominated municipalities in Finnmark County, and lower in municipalities further south ${ }^{24}$ where the Sami are in minority and where Sami self-identification is more controversial due to a more heavily assimilation process previously. ${ }^{50}$ This may have influenced the results slightly as small regional health differences have been identified in general ${ }^{26}$ and should be accounted for in future studies.

The SCL-5 was used to assess symptoms of anxiety and depression. The SCL-5 is widely used and it has previously been developed and validated as a short version of the longer SCL-25 scale. ${ }^{28}{ }^{29}$ Compared with SCL-25, SCL-5 has, in addition to good reliability, shown sound specificity $(82 \%)$ and excellent sensitivity (96\%) to detect mental health problems. ${ }^{29}$ A general limitation concerning this variable is that symptoms of anxiety and depression are assessed simultaneously.

It is unknown to what extent the results of this study represent the total Sami population and hence degree of generalisability with regard to this is unknown. One could think that Sami as an indigenous population would diverge from their non-Sami counterparts in important aspects affecting weight perception, but a high degree of similarities concerning relevant factors such as nutritional adequacy and education level as a proxy of socioeconomic status have been shown. ${ }^{11}{ }^{51}$ Accordingly, it is unknown to what extent the results from the SAMINOR 2 Clinical Survey can be generalisable to inhabitants of rural Northern Norway. However, the internal validity for the 10 included municipalities may be high.

As a result of a cross-sectional design, assessing potential causal relationships due to temporal bias was not possible. Power calculations were also difficult to do, as the strength of the studied relationships were hard to predict. The data used in this paper are part of a much larger data collection that was already conducted when we developed the research questions for this paper. Hence, increasing the sample size based on power calculations would not be possible.

\section{CONCLUSION}

In Sami and non-Sami adults with overweight/obesity living in shared regions in Northern Norway, a higher proportion of men underestimated their weight compared with women. Compared with non-Sami women, Sami women were more likely to underestimate their weight. In Sami men and non-Sami women, statistical evidence showed that underestimation of weight was protective against symptoms of anxiety and depression.

\section{Author affiliations}

${ }^{1}$ Centre for Sami Health Research, Department of Community Medicine, UiT Arctic University of Norway, Troms $\emptyset$, Norway

${ }^{2}$ Department of Public Health and Nursing, Norwegian University of Science and Technology, Trondheim, Norway

${ }^{3}$ Centre for Sami Health Research, Department of Community Medicine, UiT Arctic University of Norway, Troms $\emptyset$, Norway 
${ }^{4}$ Sámi Norwegian National Advisory Unit on Mental Health and Substance Abuse (SANKS), Finnmarkssykehuset HF, Karasjok, Norway

${ }^{5}$ University Hospital of North Norway Harstad Site, Harstad, Norway

Acknowledgements The Centre for Sami Health Research at UiT The Arctic University of Norway conducted the survey. The authors would like to thank the participants for their valuable contributions. The publication charges for this article have been funded by a grant from the publication fund of UiT The Arctic University of Norway.

Contributors KK was the PI of the study and was responsible for the design, statistical analysis and writing of the manuscript. MM, AS and ARB reviewed the project proposal. MM and ARB contributed to collecting the data. All coauthors have critically reviewed the study, made improvements of the manuscript revisions and approved the final manuscript.

Funding The SAMINOR 2 Clinical Survey was financed by the Norwegian Ministry of Health and Care Services; the Northern Norway Regional Health Authority; the Regional Research Fund of Northern Norway; the Sami Parliament; the Sami Norwegian National Advisory Unit on Mental Health and Substance Use; Finnmark, Troms, and Nordland County Councils.

Map disclaimer The depiction of boundaries on the map(s) in this article does not imply the expression of any opinion whatsoever on the part of BMJ (or any member of its group) concerning the legal status of any country, territory, jurisdiction or area or of its authorities. The map(s) are provided without any warranty of any kind, either express or implied.

Competing interests None declared.

Patient consent for publication Obtained.

Ethics approval This study was conducted according to the Helsinki Declaration and all procedures involving human subjects were approved by the Regional Committee for Medical and Health Research Ethics North Norway (reference no. 2016/985) in addition to approval from the SAMINOR Project Board.

Provenance and peer review Not commissioned; externally peer reviewed.

Data availability statement Data are available on reasonable request.

Open access This is an open access article distributed in accordance with the Creative Commons Attribution Non Commercial (CC BY-NC 4.0) license, which permits others to distribute, remix, adapt, build upon this work non-commercially, and license their derivative works on different terms, provided the original work is properly cited, appropriate credit is given, any changes made indicated, and the use is non-commercial. See: http://creativecommons.org/licenses/by-nc/4.0/.

\section{REFERENCES}

$1 \mathrm{Ng} \mathrm{M}$, Fleming T, Robinson M, et al. Global, regional, and national prevalence of overweight and obesity in children and adults during 1980-2013: a systematic analysis for the Global Burden of Disease Study 2013. Lancet 2014;384:766-81.

2 Rokholm B, Baker JL, Sørensen TIA. The levelling off of the obesity epidemic since the year 1999-a review of evidence and perspectives. Obes Rev 2010;11:835-46.

3 Kopelman P. Health risks associated with overweight and obesity. Obes Rev 2007;8 Suppl 1:13-17.

4 Jang $\mathrm{H}-\mathrm{Y}, \mathrm{Ahn} \mathrm{J}-\mathrm{W}$, Jeon M-K. Factors affecting body image discordance amongst Korean adults aged 19-39 years. Osong Public Health Res Perspect 2018;9:197-206.

5 Langellier BA, Glik D, Ortega AN, et al. Trends in racial/ethnic disparities in overweight self-perception among US adults, 19881994 and 1999-2008. Public Health Nutr 2015;18:2115-25.

6 Dorsey RR, Eberhardt MS, Ogden CL. Racial/ethnic differences in weight perception. Obesity 2009;17:790-5.

7 J.T. S. The Sámi people: a handbook. Oslo, Norway: Davvi Girji, 2006.

8 Storm Mienna C, Axelsson P. Somatic health in the Indigenous Sami population - a systematic review. Int J Circumpolar Health 2019;78:1638195.

9 Swami V, Tovée MJ. Perceptions of female body weight and shape among Indigenous and urban Europeans. Scand J Psychol 2007;48:43-50.

10 Preiss K, Brennan L, Clarke D. A systematic review of variables associated with the relationship between obesity and depression Obes Rev 2013;14:906-18.
11 Kvaløy K, Melhus M, Silviken A, et al. Disordered eating in Sami and non-Sami Norwegian populations: the SAMINOR 2 clinical survey. Public Health Nutr 2018;21:1094-105.

12 Christoph MJ, Jarrett ES, Gower AL, et al. Weight status and weight perception in relation to mental distress and psychosocial protective factors among adolescents. Acad Pediatr 2018;18:51-8.

13 Markowitz S, Friedman MA, Arent SM. Understanding the relation between obesity and depression: causal mechanisms and implications for treatment. Clin Psychol Sci \& Pract 2008;15:1-20.

14 Friedman KE, Reichmann SK, Costanzo PR, et al. Body image partially mediates the relationship between obesity and psychological distress. Obes Res 2002;10:33-41.

15 Hayward J, Millar L, Petersen S, et al. When ignorance is bliss: weight perception, body mass index and quality of life in adolescents. Int J Obes 2014;38:1328-34.

16 Heard C, Scuffham PA, Ratcliffe J, et al. The association between misperceptions around weight status and quality of life in adults in Australia. Health Qual Life Outcomes 2017;15:53.

17 Park S, Lee S, Hwang J, et al. The impact of weight misperception on health-related quality of life in Korean adults (KNHANES 2007-2014): a community-based cross-sectional study. BMJ Open 2017;7:e016098.

18. Thurston IB, Sonneville KR, Milliren CE, et al. Cross-Sectional and prospective examination of weight misperception and depressive symptoms among youth with overweight and obesity. Prev Sci 2017;18:152-63.

19 Kim D-S, Kim H-S, Cho Y, et al. The effects of actual and perceived body weight on unhealthy weight control behaviors and depressed mood among adult women in Seoul, Korea. J Prev Med Public Health 2008;41:323-30

20 Kim Y, Austin SB, Subramanian SV, et al. Body weight perception, disordered weight control behaviors, and depressive symptoms among Korean adults: The Korea National Health and Nutrition Examination Survey 2014. PLoS One 2018;13:e0198841.

21 Nystad T, Melhus M, Brustad M, et al. Ethnic differences in the prevalence of general and central obesity among the Sami and Norwegian populations: the SAMINOR study. Scand J Public Health 2010;38:17-24.

22 Lund E, Melhus M, Hansen KL, et al. Population based study of health and living conditions in areas with both Sámi and Norwegian populations - the SAMINOR study. Int J Circumpolar Health 2007;66:113-28.

23 Brustad M, Hansen KL, Broderstad AR, et al. A population-based study on health and living conditions in areas with mixed Sami and Norwegian settlements - the SAMINOR 2 questionnaire study. Int J Circumpolar Health 2014;73:23147.

24 Broderstad AR, Hansen S, Melhus M. The second clinical survey of the population-based study on health and living conditions in regions with Sami and Norwegian populations - the SAMINOR 2 clinical survey: performing indigenous health research in a multiethnic landscape. Scand J Public Health 2019;388:140349481984557.

25 Michalsen VL, Kvaløy K, Svartberg J, et al. Change in prevalence and severity of metabolic syndrome in the Sami and non-Sami population in rural Northern Norway using a repeated cross-sectional population-based study design: the SAMINOR study. BMJ Open 2019;9:e027791.

26 Naseribafrouei A, Eliassen B-M, Melhus M, et al. Ethnic difference in the prevalence of pre-diabetes and diabetes mellitus in regions with Sami and non-Sami populations in Norway-the SAMINOR1 study. Int J Circumpolar Health 2016;75:31697.

27 Siri SRA, Eliassen BM, Jacobsen BK, et al. Changes in conventional cardiovascular risk factors and the estimated 10-year risk of acute myocardial infarction or cerebral stroke in Sami and non-Sami populations in two population-based cross-sectional surveys: the SAMINOR study. BMJ Open 2019;9:e028939.

28 Tambs K, Moum T. How well can a few questionnaire items indicate anxiety and depression? Acta Psychiatr Scand 1993;87:364-7.

29 Strand $\mathrm{BH}$, Dalgard OS, Tambs K, et al. Measuring the mental health status of the Norwegian population: a comparison of the instruments SCL-25, SCL-10, SCL-5 and MHI-5 (SF-36). Nord J Psychiatry 2003;57:113-8.

30 von Elm E, Altman DG, Egger M, et al. The strengthening the reporting of observational studies in epidemiology (STROBE) statement: guidelines for reporting observational studies. Lancet 2007;370:1453-7.

31 Muttarak R. Normalization of plus size and the danger of unseen overweight and obesity in England. Obesity 2018;26:1125-9.

32 Bennett GG, Wolin KY. Satisfied or unaware? Racial differences in perceived weight status. Int J Behav Nutr Phys Act 2006;3:40.

33 Hansen KL. Ethnic discrimination and health: the relationship between experienced ethnic discrimination and multiple health 
domains in Norway's rural SAMI population. Int J Circumpolar Health 2015;74:25125.

34 Stunkard AJ, Sørensen T, Schulsinger F. Use of the Danish adoption register for the study of obesity and thinness. Res Publ Assoc Res Nerv Ment Dis 1983;60:115-20.

35 Caleyachetty R, Kengne AP, Muennig P, et al. Misperception of body weight among overweight or obese adults in Mauritius. Obes Res Clin Pract 2016;10:216-9.

36 Gibbs HD, Pacheco C, Yeh H-W, et al. Accuracy of weight perception among American Indian tribal college students. Am J Prev Med 2016;51:e139-44.

37 Lee E-Y, Myre M, Hwang J, et al. Body weight misperception and psychological distress among young South Korean adults: the role of physical activity. Glob Health Res Policy 2017;2.

38 Hassan S, Ojo T, Galusha D, et al. Obesity and weight misperception among adults in the Eastern Caribbean Health Outcomes Research Network (ECHORN) Cohort Study. Obes Sci Pract 2018;4:367-78.

39 Fang K, Li H, Ma A, et al. Weight underestimation for adults in Beijing and its association with chronic disease awareness and weight management. Lipids Health Dis 2018;17:225.

40 Klos LA, Sobal J. Marital status and body weight, weight perception, and weight management among U.S. adults. Eat Behav 2013;14:500-7.

41 Sonneville KR, Thurston IB, Milliren CE, et al. Helpful or harmful? Prospective association between weight misperception and weight gain among overweight and obese adolescents and young adults. Int J Obes 2016;40:328-32.
42 Changing the weight-loss subject. JAMA 2017;317:2477.

43 Robinson E, Haynes A, Sutin AR, et al. Telling people they are overweight: helpful, harmful or beside the point? Int $J$ Obes 2017;41:1160-1.

44 Puhl RM, Heuer CA. Obesity stigma: important considerations for public health. Am J Public Health 2010;100:1019-28.

45 Cash TF. Body image: past, present, and future. Body Image 2004;1:1-5.

46 Byeon $\mathrm{H}$. Association between weight misperception patterns and depressive symptoms in Korean young adolescents: national crosssectional study. PLoS One 2015;10:e0131322.

47 Xie B, Chou C-P, Spruijt-Metz D, et al. Weight perception, academic performance, and psychological factors in Chinese adolescents. Am $J$ Health Behav 2006;30:115-24.

48 Xie B, Liu C, Chou CP, et al. Weight perception and psychological factors in Chinese adolescents. J Adolesc Health 2003;33:202-10.

49 Park JY, Mitrou PN, Keogh RH, et al. Effects of body size and sociodemographic characteristics on differences between self-reported and measured anthropometric data in middleaged men and women: the EPIC-Norfolk study. Eur J Clin Nutr 2011;65:357-67.

50 Minde $\mathrm{H}$. Assimilation of the Sami-implementation and consequences. Acta Borealia 2003;20:121-46.

51 Petrenya N, Skeie G, Melhus M, et al. No ethnic disparities in nutritional adequacy between the Indigenous Sami and the non-Sami population living in rural Northern Norway-the SAMINOR 2 clinical survey. Nutr Res 2019;64:9-23. 